\title{
IS ICT SMARTNESS POSSIBLE DEVELOPMENT WAY FOR HUNGARIAN RURAL AREAS?
}

\author{
Henrietta Nagy, Jozsef Kaposzta, Adrienn Varga-Nagy \\ Szent Istvan University, Hungary \\ nagy.henrietta@gtk.szie.hu, kaposzta.jozsef@gtk.szie.hu,varga.nagy.adrienn@gtk.szie.hu
}

\begin{abstract}
The aim of this study is to introduce some EU development strategies on smart cities and villages to see whether smartness can be a suitable development method for the rural areas. Such strategies are getting more and more importance and emphasis all over the world. In many developed countries, becoming smart is basically equal to developed technology and ICT. It might be a way for cities with developed infrastructure, but it might not be the proper way of development for the disadvantaged rural areas. Due to the great territorial discrepancies not only in Europe as a whole, but within several countries of the continent, the existing smart strategies may provide assistance for the developed cities, but not for the countryside. At present, for strategy-makers, smartness refers to high quality infrastructure, technology that requires highly qualified human resource. The latter one is available mainly in urban areas, but the human resource in many rural areas (ageing, unemployed, poorly qualified etc.) is not able to use high tech and modern ICT. Therefore, smartness for them should mean something else and the same strategies cannot be applied in such underdeveloped areas (where high rate of population live). After the overview on some major existing strategies, we intend to evaluate the human resource tendencies as one of the most significant precondition to become smart for rural areas. Our primary focus is the least-developed region of Hungary, but we aim to provide conclusions for a broader scope.
\end{abstract}

Keywords: rural development, smart village, smart city, ICT, human resource.

\section{Introduction}

Issues of rural development are undoubtedly in the focus of interest nowadays, since moderating the inequalities between regions is a priority for all national governments. Many deal with the increasingly hot problems of rural development that influence the urban areas as well by now. We can state that national governments globally are interested in the achievements of spatial development, have great influence on its development, especially to direct it to the right path from the society's aspect. Over the history, the Hungarian society was able to renew itself based on the strengths of communities in the villages and from rural roots. The countryside is not only a scene of production, producing profit, but the complexity of social, cultural and natural values [1]. Rural areas are the scenes of living and harmonious co-existence of nature and the society formed over the history. On the one hand, such areas provide the living conditions for the population, on the other hand, unique ecosystem-services that offer safe food supply, good environment, natural resources and values as well as recreational opportunities for the whole society. Therefore, the issues of the countryside are not only the business of rural population, but it is the interest of the whole society. The development of rural areas and setting the strategy for the planning are unavoidable while planning the future.

\section{Smart approaches}

According to UNCTAD [2], "globally, creative industries are estimated to account for more than 7 per cent of the world's gross domestic product and are forecast to grow, on average, by 10 per cent a year". To create an environment in which people and businesses can succeed, a stable macroeconomic environment is an essential condition. Upon that foundation we can create the conditions for supply side success: high levels of education for people of all ages, first-class transport and telecommunications infrastructure, a favorable regulatory and tax framework.

Nowadays, there are two processes going on in the world and, of course, in the European Union: more and more people tend to move to urban areas searching for better quality of life, jobs, more and better services, greener environment etc. while there are more and more underdeveloped regions losing their attractiveness for investments, having poor infrastructure, having ageing and underqualified population, providing low-quality services in limited quantity [3], thus getting gradually uninhabited. While in 2015 , the urban population in the European Union was $72 \%$ of the total population, it is estimated that in 2050 this percentage will increase to $80 \%$. On the one hand, it can be considered a positive tendency and it establishes the emphasis on smart city concepts, on the other hand, it forecasts deep poverty and serious economic, social and environmental problems in the 
rural areas. Since all the countries, including Hungary, have to deal with these two processes parallel, apart from smart city concepts, smart village concepts must be also emphasized and tailored to the rural disadvantaged areas.

If not, not only the young and qualified people will move to cities, but also those, who have no potentials in the rural villages, unemployed, underqualified - sometimes criminal - people, since they also have strong need for a better life. Therefore, in long terms, the proper strategy should be defined, various measures should be taken in urban and rural areas to make them smart.

In Figure 1, features and tools are collected that characterize smart cities with strong sustainability focus. However, it is only one - even if the most common - concept, which cannot be realistically applied in disadvantaged rural areas with low number of population, poor infrastructure, underqualified human resource and difficult accessibility.

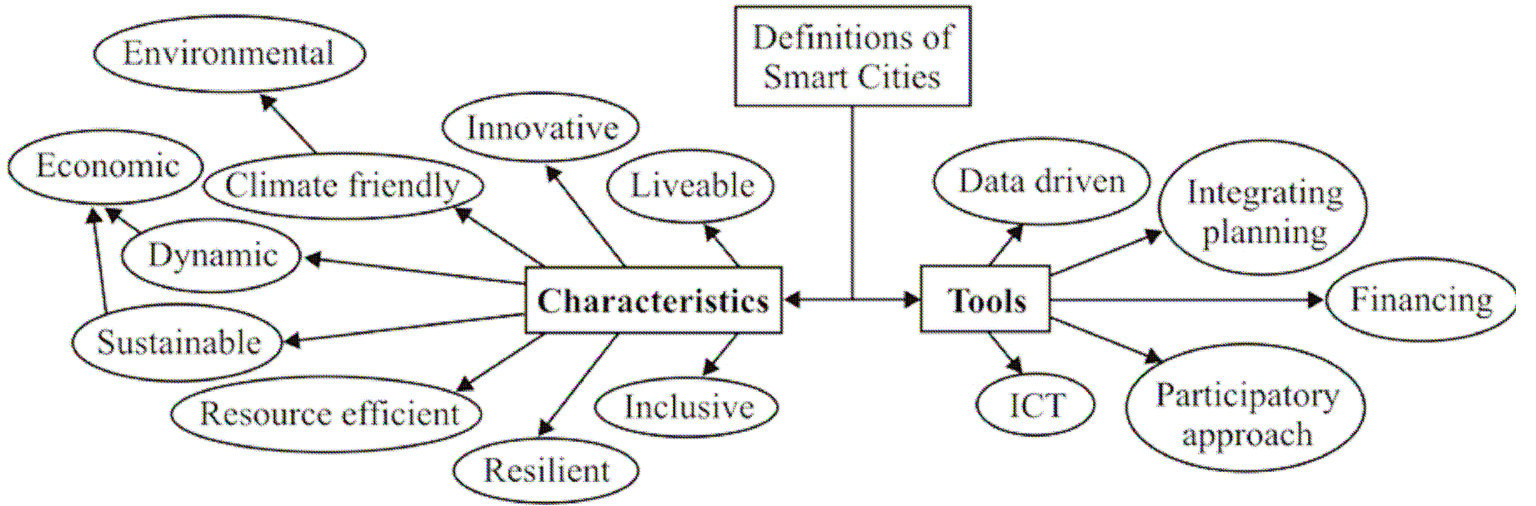

Fig. 1. Characteristics and tools used to define Smart City source: urbantransform.eu, 2017 [4]

In early September 2016, more than 340 rural stakeholders gathered in Cork, Ireland, and developed a vision for the future of the EU rural areas. Under the heading "A Better Life in Rural Areas", the Cork Declaration 2.0 sets out the expectations and aspirations of rural areas. Among the priorities to be addressed, it calls for policies to pay particular attention to overcoming the digital divide between rural and urban areas and to develop the potential offered by connectivity and digitization of rural areas. Emphasis was given to the need for integrated approaches and the interaction between different policy fields in view of increasing complementarity and coherence.

Smart Villages cannot be done in isolation and should be embedded in the wider development strategies for regions and territories. Strengthening the links between rural and urban areas is the key to achieving the EU objectives. For many people, rural areas are simply home - a place to live, work and raise families. Rural communities need jobs, basic services, connectivity and smart transport solutions as well as a favorable climate for entrepreneurship. New types of business models need to emerge, such as portal-based services, and assist existing rural businesses to connect, integrate and cooperate better with urban based business. Location of economic activity is linked to the recognition of the "geographical capital" and other possible comparative advantages for specialization or diversification. Intelligent logistics networks would allow villages to provide their products and services more efficiently on urban and global markets. The EU rural areas are places of great assets and they can become even more attractive, if local actors can unlock their potential. They provide indispensable contributions to solve many of the big societal challenges, such as climate change or the sustainable provision of food, biomass and energy [5]. They have unlimited potentials for tourism and culture with their rich values, but the development of such sectors needs conscious planning. Tourism can encourage investments in rural areas, while their natural and cultural values may be damaged due to intensive tourism.

The concept of Smart Villages is not a one-size-fits-all solution, similarly to other spatial development strategies. It is territorially sensitive, based on endogenous resources, motivated by the needs and potentials of the respective territory. Technology is important as are investments in infrastructure, business development, human capital, capacity and community building, good governance and citizens involvement are also key issues. A Smart Village would typically pay attention to e-literacy skills, access to e-health and other basic services, innovative solutions for 
environmental concerns, circular economy application to agricultural waste, promotion of local products supported by technology and ICT, implementing and taking full benefit of smart specialization agro-food projects, tourism and cultural activities, etc., but at the moment for many rural areas and communities such are far to achieve [5]. Based on the abovementioned, it can be seen that technological development, developed infrastructure, sustainable development play an important role in Smart Villages concept as well, but to use the latest technology, the human capacities are of key importance. That was the main motivation in our research to highlight the territorial differences in human capital.

\section{Materials and methods}

In this study our aim was to give a complex overview on the human resource situation of one of the least-developed regions of Hungary to call the attention on the role of the population and give it priority instead of the latest technologies that can be efficiently used preferably in more modern cities. In our research we collected data from the Central Statistics Office of Hungary as well as the Eurostat database for all the regions of Hungary to have a much broader research but in this paper we wanted to focus on the negative extreme, i.e. the poorest region of the country. Since an overall strategy, called Europe 2020 is in effect in all the EU countries at the moment, we intended to follow the aspects of that strategy as well.

\section{Methodology}

Regarding the timeframe of the analysis, we decided to use the data of the year 2007 (the first year of the multiannual programming period when Hungary was already a full member) and the latest years available in the current programming period $(2014,2015,2016)$. It was important to see how the human resource of the regions changed - improved or not - due to the huge amount of development funds available after the EU accession. In the research, the data were collected and analyzed to see the tendencies about human resources in the target area. The data were put in Microsoft Excel and the graphs were prepared to reflect how much this region is ready to be smart and whether it has the necessary preconditions for ICT smartness. In the research we collected and analyzed data for employment, unemployment, long-term unemployment, however, in this paper - due to page number restrictions - we just intend to analyze the situation on ICT usage and digital skills of the population in the region, since all the smart concepts focus on the development of such skills and consider them as preconditions of long-term sustainable development.

\section{Results and discussion}

First, we examined the economically active population of the Northern-Hungary region. It seems to be obvious that it has been increasing. Though this is only from statistical point of view, since it is a general phenomenon that elderly people over 65 tend to have jobs and be active economically. Even if the economically active population was nearly 500,000 in 2016, it should not be considered a favorable data, since the total population of the region in that year was $1,153,714$. If we look at the numbers referring to those who have primary or lower secondary education and those with tertiary education, we can see that their tendencies show increase. On the one hand it is favorable, since more and more people take part in tertiary education, but on the other hand, it is unfavorable, since the number of those with the lowest qualification has been also increasing. From smartness point of view, such can be considered insufficient basis and only systematic and targeted measures could help improve the situation.

If we compare the number of employed people to the number of total population in the examined years, we can see that approx. $40 \%$ of the population worked only, which is not a good basis for development. If we go into the details, it calls the attention on the low number of employed with tertiary education attainment - despite of its increasing tendency. An even more serious problem is that the number of those who do not have or have only primary education and lower secondary education, also increased from nearly 50,000 (2007) to 68,700 (2016). It is almost an increase of 20,000 people $(40 \%)$. Unfortunately, this tendency is not really leading to smartness, even if the number of employed with tertiary education attainment also increases. It is still a low figure, but the 
increase is probably due to the industrial parks and the location of more and more industrial companies to the region (e.g., Bosch).

In the following graphs the abovementioned human resource figures are displayed that can be considered as preconditions of smart development.

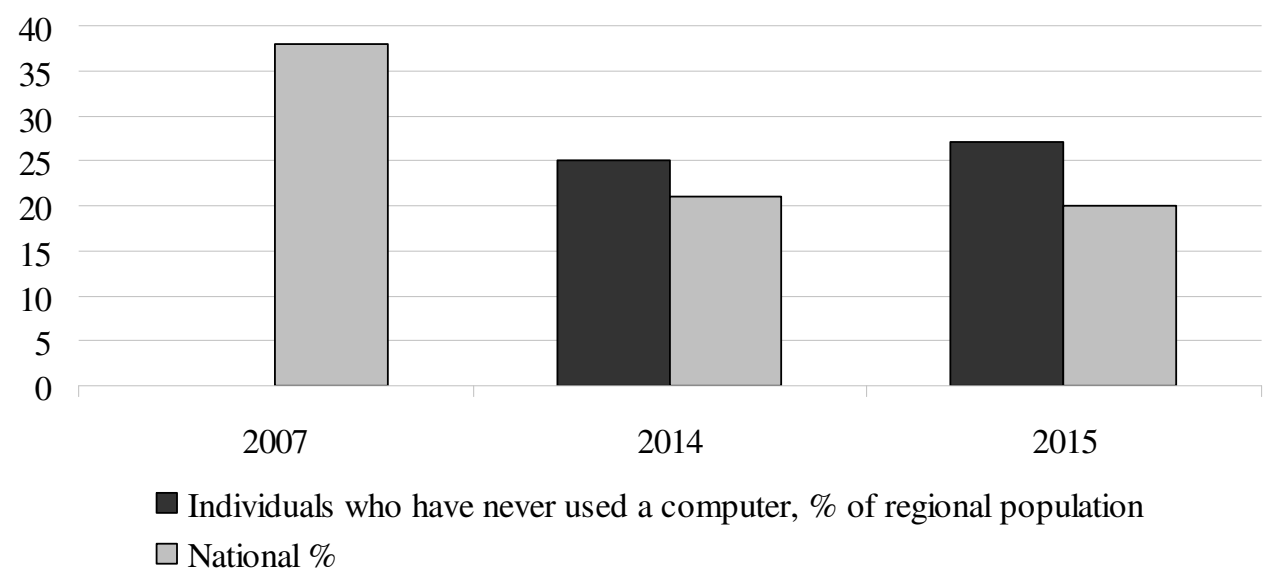

\section{Fig. 2. Share of those who have never used a computer in Northern-Hungary and in Hungary source: Eurostat, 2017 [6]}

Figure 2 can be misleading regarding the data of 2007 (no data). It should be mentioned that regional data were not available for that year that is why it is zero and no data are available for 2016 either. If we look at the regional figures of 2014 and 2015, it is obvious that they do not prove any tendencies, but the territorial difference is clear. Regarding the national rate, we can see that the rate halved from 2007 (38\%) to 2015 (20\%), while in Northern-Hungary the rate was around $25-27 \%$ in the selected years, which is still quite high. Such members of the society - in short terms - cannot be target groups of smart strategies.

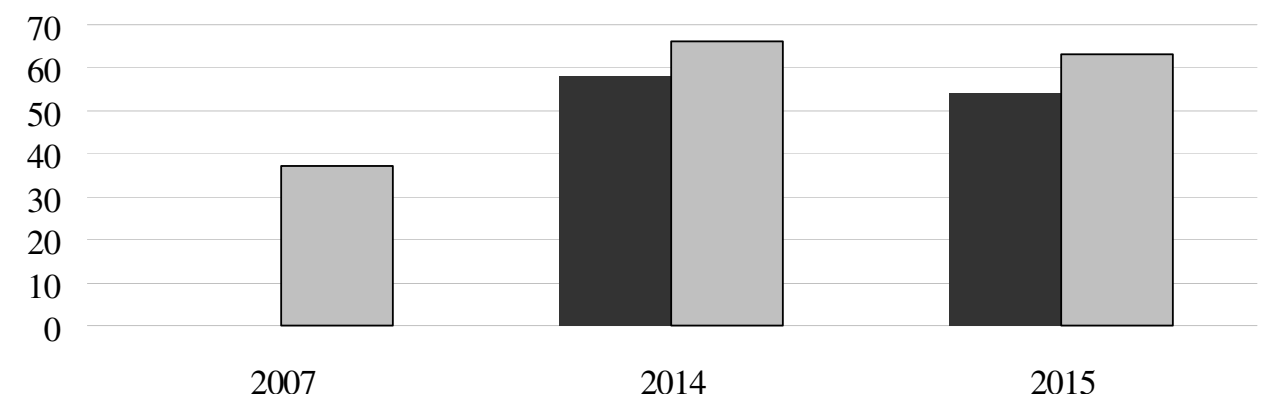

Percentage of individuals in the region who accessed the internet daily, \%

$\square$ National \%

Fig. 3. Share of those in population of the region and the country who accessed the Internet on daily basis source: Eurostat, 2017 [6]

In Figure 3 there are also missing regional data for 2007 and similarly to Figure 2, there are no data available for the year 2016. However, the figures reflect that approximately every second individual in the region accessed the Internet daily, which is still far from the national (71\%) and the EU average $(71 \%-2016)$. Such low rate reflects that they do not use the Internet even for private searches, not to mention e-commerce, work, e-governance, e-health etc.

In Figure 4, a favorable tendency can be observed nationwide, namely that in 7 years, the share of those who never used the Internet dropped from 46 to $21 \%$ by 2014, while in the region the picture is not so promising. The share is still around $25-28 \%$, which is higher than the national and the EU average $(16 \%-2015)$. If we consider the fact that the Internet is used for various purposes nowadays 
and may help our everyday life and assist in more efficient communication, the $25-28 \%$ should be considered huge and from smart development point of view it requires urgent measures.

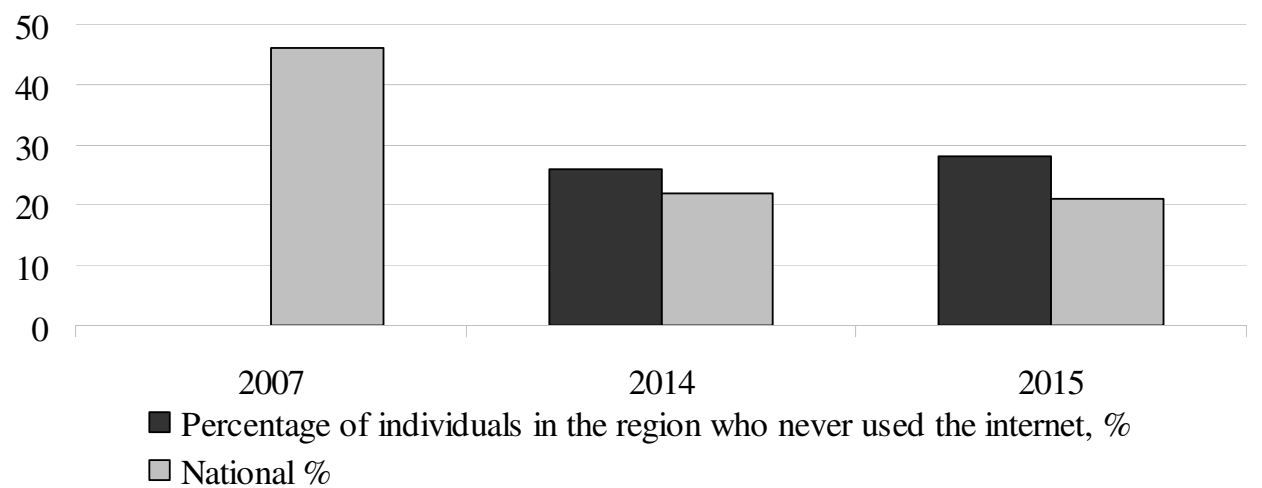

\section{Fig. 4. Share of those who have never used the Internet in \% of population of Northern-Hungary and of the country, source: Eurostat, 2017 [6]}

All these statistical figures and the Smart Village concept prove that Northern-Hungary is in one of the least favorable situations - even within the country [7]. There are huge territorial differences within Hungary, not to mention the EU as a whole, but if sustainable development is desired to achieve in the EU, more and special focus should be put on the most disadvantaged regions of the Community, having more specific human resource development measures that could serve as a basis for smart approach as well.

Regarding the human resource conditions of the regions and the targets desired by the EU, rural areas should be the focus of development strategies in education (including formal and informal education), because the more knowledge-based is the economy, the more value addition can be achieved. In order to keep the population in the countryside and stop the migration of the active population to the more developed regions, business incentives must be applied, businesses must be encouraged to locate not only in urban areas. Moreover, the infrastructure, including transportation infrastructure has to be developed. We must not decide on whether infrastructure has to be developed or other business environment elements. They have to be developed parallel and a complex integrated approach has to be followed.

\section{Conclusions}

One of the most important challenges of Hungary during its catching up with the developed countries is how the quality of life and environment as well as the local areas in the countryside could reach the development level, which is in harmony with economic growth. In order to face and address this challenge, it is important to learn the economic, social and human factors in details, since the combination of these factors may bring perspective for a given area. Many people think that rural areas are simply the scene of agricultural and food production, but they have much broader responsibility. It is the scene of life and jobs of families by providing jobs, basic services and public administration. It is important to introduce intelligent solutions in creating new business models that will have result in economic/social welfare through the development of economy. Acknowledging the "geographical capital" in the system of enterprises may allow them to join the intelligent networks and allow the villages to offer their products and services on the urban and global markets more efficiently. Due to such developments, rural areas may become more attractive. There is only one thing to do; it is to make the local players be interested in innovative developments. Therefore, the fundamental question for the Hungarian countryside is whether there is a way of development that leads to catching up with the EU member states, on which the economic underdeveloped situation can be halted, while preserving the country's valuable environmental endowments, natural resources as well as cultural and social roots. We are convinced that such a way is that of intelligent and innovative development.

The aim of this study was only to call the attention on the importance of human resource in the developments based on smart concept. This smart approach is getting more and more emphasis and getting increasing popularity in the European Union, since it may lead to moderate the territorial 
inequalities by helping the disadvantaged, underdeveloped rural areas to catch up. The EU has given priority to a concept called Smart Village in 2016 and intends to channel the already existing development policies and funds, e.g. CAP, Cohesion policy, Europe 2020, HORIZON 2020, ERDF, Connecting Europe Facility (CEF) to the target areas. This targeted focus could bring more benefits and more spectacular results to those areas that are lagging behind. As it can be seen, it is quite a new policy even in the EU, so there are not many achievements yet. We can list up some initiatives related to smart cities, but the ones related to smart villages do not exist yet. That was our motivation in getting deeper knowledge in this topic and in collecting information about the human resources in one of the least-developed regions of Hungary.

We are convinced that the territorial imbalances existing among the regions of Hungary can only be mitigated, if we have specific, targeted policies and take individual measures according to the endogenous resources of the regions. Since the ICT tools and digital skills are in the focus of the smart concepts, and most of the rural population do not have the sufficient and necessary capacities and competencies, we believe that the developments and strategies should have a priority on the development of human resource by increasing the level of their qualification, enabling them to take competitive jobs and by increasing their digital skills. We agree with Hargreaves [8] saying that investment in education and associated infrastructure is crucial for any smart city to prosper in the knowledge economy. Such investment includes

1. access to quality education for all people, including the disadvantaged;

2. education and career pathways to people of all ages for lifelong learning; and

3. improving technical infrastructure, such as broadband and video conferencing for remote areas.

In our opinion, real benefits could be achieved only if we apply a uniform system of indicators on various fields like economy, society, innovation, governance, energy-supply, sustainability, transportation, health, ICT usage, telecommunication, housing, wastewater etc. to be able to compare the regions to each other with realistic targets set and adjusted to the local resources and needs.

\section{Acknowledgements}

„Supported BY the ÚNKP-17-3 and ÚNKP-17-4-III-18 New National Excellence Program of the Ministry of Human Capacities"

\section{References}

[1] Gál T., Nagy L., Dávid L., Vasa L., Balogh P. Technology planning system as a decision support tool for dairy farms in Hungary. Acta Polytechnica Hungarica 10:(8) pp. 231-244. (2013)

[2] UNCTAD. Creative Industries and Development. 2004 [online] [31.01.2018]. Available at: http://unctad.org/en/docs/tdxibpd13_en.pdf, p. 14.

[3] Káposzta J., Némediné Kollár K. Smart települési modellek vizsgálata nemzetközi és hazai kezdeményezések alapján, avagy mi lehet a minta a periférián? (The examination of smart settlement models based on international and national initiatives, what could be the pattern in the peripheral areas?), Studia Mundi-Economica, Vol. 4. No. 3., pp. 57-66, 2017 (in Hungarian) [online] [05.02.2018]. ISSN 2415-9395, DOI 10.18531/Studia.Mundi.2017.04.03.57-66

[4] Transform website. [online] [05.02.2018]. Available at: urbantransform.eu.

[5] EU Action for Smart Villages. EU Commission. p. 8. [online] [02.01.2018]. Available at: https://ec.europa.eu/agriculture/sites/agriculture/files/rural-development-2014-2020/lookingahead/rur-dev-small-villages_en.pdf.

[6] Eurostat, [online] [20.11.2017]. Available at: http://ec.europa.eu/eurostat/data/database

[7] Pénzes J., Bujdosó Z., Dávid L., Radics Zs., Kozma G. Differing development path of spatial income inequalities after the political transition - by the example of Hungary and its regions. Ekonomika Regiona/Economy of Region 2014:(1) pp. 73-84. (2014)

[8] Hargreaves A. Teaching in the knowledge society. New York, NY: Teachers College Press, 2003. 